\title{
INTERNAL STRESSES AND DISLOCATION STRUCTURE OF LOW-CARBON STEEL AFTER ELECTROLYTE-PLASMA NITROCEMENTATION
}

\author{
BAYATANOVAL.B. ${ }^{1}$, RAKHADILOVB.K. ${ }^{2,3}$, SATBAYEVA Z.A. ${ }^{2,3}$, POPOVAN.A. ${ }^{4}$ \\ ${ }^{I}$ D.Serikbayev East-Kazakhstan State Technical University, Ust-Kamenogorsk \\ ${ }^{2}$ S.Amanzholov East-Kazakhstan State University, Ust-Kamenogorsk, Kazakhstan \\ ${ }^{3}$ TOO «PlasmaScience», Ust-Kamenogorsk, Kazakhstan \\ ${ }^{4}$ Tomsk State University of Architecture and Building, Tomsk, Russia
}

\begin{abstract}
In this article, we studied the influence of electrolytic-plasma carbonitriding on the dislocation structure and longrange stress fields of low carbon steel 18HN3MA-SH. Shear stresses and momentary stresses $\sigma_{o}$ in all morphological components of the $\alpha$-phase and in general for the material for steel 18HN3MA-SH were calculated in the initial state and after exposure to electrolytic plasma. The sources of internal stresses in the studied steel are determined. Research have shown that after carbonitriding in electrolytic plasma, the shape of the particles of the phases present in steel, their size and mutual arrangement are different, and also, the particles of all phases are surrounded by the o-matrix. Compared with the initial state of steel, the torque stresses were significantly lower, i.e. electrolyte-plasma carbonitriding led to a decrease in internal stresses.

KEYWORDS: Electrolyte Plasma, Carbonitriding, Steel, Fine Structure, Dislocation, Long-Range Stress Fields
\end{abstract}

Received: Jun 08, 2020; Accepted: Jun 28, 2020; Published: Sep 22, 2020; Paper Id.: IJMPERDJUN20201379

\section{INTRODUCTION}

Despite of numerous methods of chemical-heat treatment of machine parts, the search for alternatives to more energy-saving, productive, environmentally friendly methods is an actual task.One of such methods is a method of electrolytic-plasma treatment (EPT) [1]. EPT is an electrochemical process of hardening of the surface layer in combination with electric discharge phenomena at the boundary - working electrode - aqueous electrolyte solution. As a result, the surface layer is modified by electrolyte ions, with the flow of electric current, the structure of which by its multifunctional technological characteristics significantly exceeds the coatings obtained by traditional methods.

It is known that the residual stresses are the main feature of the material subjected to cementation and especially to nitriding. In the surface hardened layer, compressive stresses are created, in the middle - tensile. They can reach significant values, especially with changing configuration of parts. For such steels, which was investigated in the present work, these stresses vary within 80-200 MPa - compressive, and tensile stresses outside the layer vary within 80-400 MPa [2]. It must be emphasized that the internal stress fields play an important role in the formation of yield strength, strain hardening and in the origin and opening of microcracks. Large stresses can lead to the initiation of microcracks and, ultimately, the destruction of the product. Their role is also significant in the evolution of the defective structure during phase and structural transformations [3,4]. Therefore, special 
attention in this paper was given to the problem of internal potentials.

The aim of this work was to research the dislocation structure and long-range stress fields in steel 18HN3MA-SH before and after carbonitriding in electrolyte plasma.

\section{EXPERIMENTAL}

The researches were carried out by methods of electron diffraction microscopy on thin foils using a JEOL-2100 electron microscope using goniometric attachments at an accelerating voltage of $100 \mathrm{kV}$. The working increasing in the microscope column was chosen from 10,000 to 50,000 times.

As a study material used samples of structural steel 18HN3MA-SH $(0.16-0.18 \% \mathrm{C} ; 3.3 \% \mathrm{Ni} ; 0.9 \% \mathrm{Cr} ; 0.51 \% \mathrm{Mo}$; $0.44 \% \mathrm{Mn} ; 0.34 \%$ ) were used as the study material. $\mathrm{Si} ; 0.05 \% \mathrm{Al} ; 0.008 \% \mathrm{~S} ; 0.012 \% \mathrm{P} ; 0.015 \% \mathrm{~N} ; 0.01 \% \mathrm{O} ; 0.01 \% \mathrm{H}$ ) (GOST 4543-71) after electrolytic-plasma carbonitriding $\left(850^{\circ} \mathrm{C}, 5 \mathrm{~min}\right.$.) [5].

\section{RESULTS AND DISCUSSIONS}

As conducted research have shown, the steel 18HN3MA-SHin the initial condition belongs to the ferrite-pearlite class and consists of ferrite grains $(\sim 20 \%)$ and pearlite $(\sim 80 \%)$ (Fig. 1). In turn, the internal structure of ferrite grains is a mixture of three morphological components, perlite grains - four. Namely, the composition of ferrite grains includes: 1) unfragmented ferrite, 2) fragmented ferrite with large $(\sim 0.9 \mu \mathrm{m})$ and 3$)$ with small $(\sim 0.3 \mu \mathrm{m})$ fragments. Pearlite grains are a mixture of 1) weakly defective perlite, 2) broken pearlite, 3) fragmented pearlite and 4) fragmented structure with M23C6 carbide particles. All components of ferrite and perlite have a different set (qualitative and quantitative) of carbide phases and are characterized by different scalar and excessive dislocation densities.

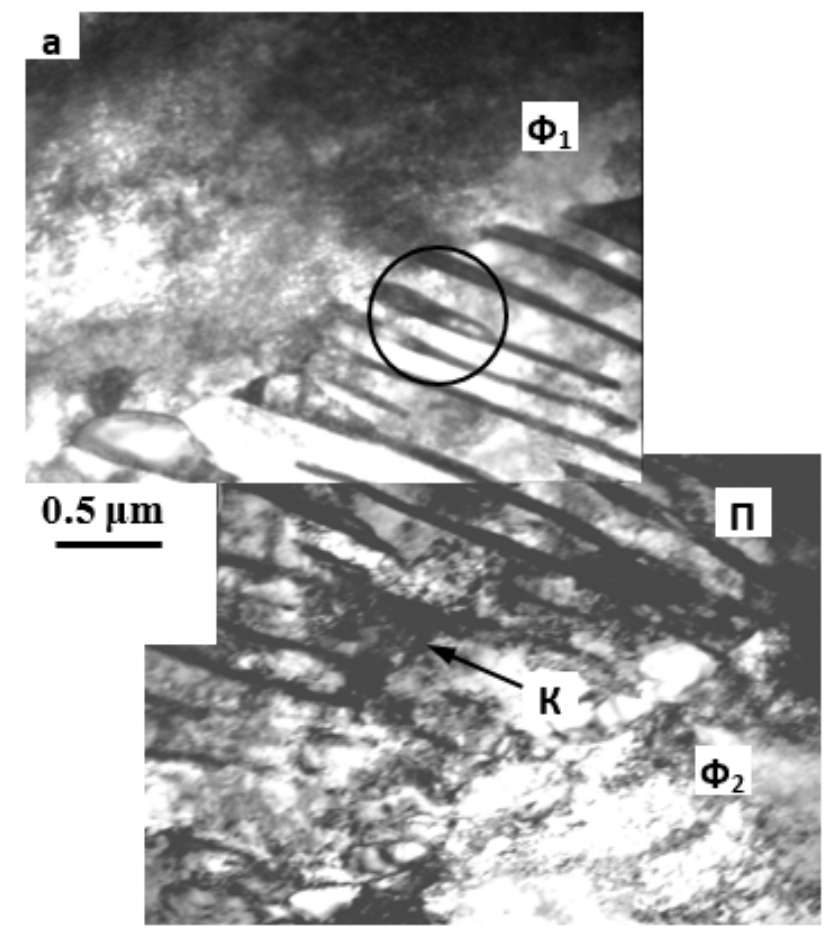

A circle on (a) marked cementite plates with growths - "cementite bridges". $\mathrm{K}$ - bending extinction contour

Figure 1: Electron-microscopic image of the structure of steel 18HN3MA-SH in the initial condition. Pearlitic grain $(P)$ between the grains and ferrite $\left(F_{1}\right.$ and $\left.F_{2}\right)$ 
The quantitative characteristics of the dislocation structure in various morphological components of ferrite and perlite are given in table 1 . As can be seen from the table, the average scalar density of dislocations in ferritic grains is almost 2 times less than in pearlitic ones. It is also seen from the table that among the morphological components of ferrite, the greatest value of $\rho$ is unfragmented ferrite, the smallest is fragmented ferrite with small fragments. This is not surprising, since It is known that the scalar density of dislocations is associated with the size of grains or fragments containing a network dislocation structure, a straight line dependence [6]. This means that in fragmented ferrite with small fragments, the value of $\rho$ should be lower, which is observed in the studied steel.

In perlite grains, the highest value of $\rho$ is fragmented perlite, the lowest - fragmented structure with $\mathrm{M}_{23} \mathrm{C}_{6}$ particles. This also agrees well with the literature data. It is known [7] that anisotropic fragments with a reticular dislocation structure are formed underthe destruction of pearlite. At the boundaries of the fragments there are lamellar particles of cementite, entangled by dislocations. Scalar density increases rapidly. Upon further destruction of the pearlite structure, carbon leaves the cementite lattice, cementite plates are destroyed, special type carbides are formed, fragments of fragments are cleared of carbon atoms and dislocations, misorientation at boundaries increases, and fragments of borders become similar to subgrain-type boundaries, the density of dislocations inside fragments falls that well reflect in the table 1.

Table 1: Quantitative characteristics of the dislocation structure in different morphological components of ferrite and perlite in steel 18HN3MA-SHin the initial condition

\begin{tabular}{|c|c|c|c|}
\hline \multirow{2}{*}{ Morphological components } & $\mathbf{P}_{\mathbf{V}}$ & $\rho\left(\times 10^{10}\right)$ & $\rho_{ \pm}\left(\times 10^{10}\right)$ \\
\hline & $\%$ & $\mathrm{CM}^{-2}$ & $\mathbf{C M}^{-2}$ \\
\hline \multicolumn{4}{|c|}{ Perlite grains } \\
\hline Unfragmentedferrite & $5 \%$ & 3.5 & 1.7 \\
\hline Fragmentedferrite (largefragments) & $10 \%$ & 3.1 & 3.1 \\
\hline Fragmentedferrite (small fragments) & $5 \%$ & 1.2 & 1.2 \\
\hline In ferritegrains & $20 \%$ & 2.7 & 0.5 \\
\hline \multicolumn{4}{|l|}{ Perlite grains } \\
\hline Weaklydefectiveperlite & $5 \%$ & 2.3 & 1.7 \\
\hline Destroyedpearlite & $10 \%$ & 2.2 & 2.2 \\
\hline Fragmentedperlite & $55 \%$ & 1.5 & 1.5 \\
\hline Fragmented structure with parts of $\mathrm{M}_{23} \mathrm{C}_{6}$ & $10 \%$ & 5.3 & 5.3 \\
\hline In perlite grains & $80 \%$ & 2.1 & 2.1 \\
\hline Materialaverage & $100 \%$ & 2.2 & 1.8 \\
\hline
\end{tabular}

The characteristics of stress fields can be measured by optical and magnetic methods in physical research. However, these methods are integral methods. The area of stress averaging using these methods is centimeters.

Fields of stress can be determined using X-ray analysis (measurement of stresses of I and IItypes). The area of stress averaging in this case is significantly reduced (millimeters), but still remains large.

Only the application of diffraction electron microscopy method allows you to adjust the locality of the measurement of stress fields in a wide range (from one tenth to hundreds of microns). The values of stress fields are restored by the pattern of material structure in several ways: 1) by the bending radius of free dislocations of segments [8], 2) by the distance between dislocations and the parameters of dislocation clusters [9], 3) by the distance between active slip planes [10] and, finally, 4) by the parameters of bending extinction contours [11]. 
It should be noted that the internal stresses determine the shape of the material during annealing and can lead to permanent deformations. Particularly dangerous stress concentrators in local areas of the material. Therefore, the fourth method of measuring the amplitude of stress fields (by the parameters of bending extinction contours) using diffraction electron microscopy was used to study the internal stress fields in steel 18XH3MA-Ш.

An uncharged dislocation ensemble (i.e., an ensemble without excessive dislocations) gives a shear stress (stress fields created by the dislocation structure), defined by the formula [12]:

$$
\sigma=\alpha G b \sqrt{\rho}
$$

where $\alpha$-changing within 0.05-1.0 depending on the type of dislocation ensemble [13] (for a charged dislocation ensemble, the value of the coefficient $\alpha=0.625$ [13]); $G$ - the shear modulus, $b$ - the Burgers vector; $\rho$ - the scalar density of dislocations.

In the case of a charged dislocation ensemble, when the excess density of dislocations:

$\rho_{ \pm}=\rho_{+}-\rho_{-} \neq 0$

torque stresses are created and then the relation is used:

$$
\sigma_{\partial}=\alpha_{C} G b \sqrt{\rho_{ \pm}}
$$

where $\alpha_{c}=1-$ Strunin coefficient [14].

As we see from Table 1, the heat treatment of steel led to the accumulation in it of a high scalar dislocation density, reaching values of $2.2 \cdot 10^{10} \mathrm{~cm}^{-2}$. Such a dislocation structure, in turn, should form large internal stresses.

The dislocation structure formed in the heat-treated steel along with the scalar density of dislocations is characterized by a high value of the excess density of dislocations (Table 1). The latter also causes high internal stress fields (momentary stresses), which are identified by the presence of extinction circuits in the material. As can be seen from Table 1 , the scalar dislocation density $\rho$ is almost equal to the excess dislocation density $\rho_{ \pm}$, i.e. $\rho \approx \rho_{ \pm}$. All this means that the scalar dislocation ensemble is fundamental in the formation of the internal stress field.

Thus, the main sources of internal stress fields already in the initial state of the steel under the research are: 1) scalar dislocation density and 2) polarization of the dislocation structure and excess dislocation density.

The conditions of heat treatment of steel, as we have already noted, led to the creation of significant internal stresses. We recall once more that their action is manifested in the appearance of a bending-torsion of the $\alpha$-phase crystal lattice. In electron microscopic examination, it is found in the form of extinction contours, the thickness of which is inversely proportional to the amplitude of the bending-torsion of the crystal lattice. It is known that the bending-torsion of the lattice can be plastic and elastic. In the first case, it is caused by dislocation charges, i.e. excessive density of dislocations, localized in a certain volume of the material [11]. In the second, unrelaxed elastic stresses accumulated due to incompatibility of deformation, for example, grains [15]. Elastic-plastic bending is also possible when both sources of fields are present in the material [16]. It is this bending-torsion that is observed in the steel under study in the initial state (Table 2). 
Table 2: The amplitude of the curvature-torsion of the crystal lattice and its components in different morphological components of ferrite and perlite in steel 18HN3MA-SH in the initial condition

\begin{tabular}{|c|c|c|c|c|}
\hline \multirow[t]{2}{*}{ Morphological components } & \multirow{2}{*}{$\begin{array}{l}\mathbf{P}_{\mathbf{V}} \\
\%\end{array}$} & \multicolumn{3}{|c|}{$\begin{array}{l}\text { The amplitude of the curvature-torsion of the } \\
\text { crystal lattice, } \chi[\mathrm{rad} / \mathrm{cm}]\end{array}$} \\
\hline & & $\langle\chi\rangle$ & $\chi_{\text {пл. }}$ & $\chi_{\text {vпр. }}$ \\
\hline \multicolumn{5}{|c|}{ Perlite grains } \\
\hline Unfragmentedferrite & $5 \%$ & 425 & 425 & 0 \\
\hline Fragmentedferrite (largefragments) & $10 \%$ & 920 & 920 & 0 \\
\hline Fragmentedferrite (small fragments) & $5 \%$ & 4360 & 300 & 4060 \\
\hline In ferritegrains & $20 \%$ & 1660 & 640 & 1020 \\
\hline \multicolumn{5}{|l|}{ Perlite grains } \\
\hline Weaklydefectiveperlite & $5 \%$ & 440 & 440 & 0 \\
\hline Destroyedpearlite & $10 \%$ & 1450 & 550 & 900 \\
\hline Fragmentedperlite & $55 \%$ & 2910 & 1325 & 1580 \\
\hline Fragmented structure with parts of $\mathrm{M}_{23} \mathrm{C}_{6}$ & $10 \%$ & 2910 & 370 & 2540 \\
\hline In perlite grains & $80 \%$ & 2570 & 1050 & 1520 \\
\hline Materialaverage & $100 \%$ & 2390 & 970 & 1420 \\
\hline
\end{tabular}

Using formulas (1) and (2), shear stresses $\sigma$ and moment stresses $\sigma_{\partial}$ were calculated in all the morphological components of $\alpha$-phase and in general for the material for steel 18HN3MA-SHin the initial state. The obtained data are presented in table 3. It is clearly seen that, firstly, in almost all morphological components of the $\alpha$-phase, the amplitude of the moment stresses is higher than the amplitude of the shear stress, secondly, in all the morphological components of the $\alpha$-phase there is an elastic-plastic bend of the crystal lattice .

As a result of carbonitriding in electrolyte plasma, a nitro-cemented layer was formed near the surface of the treated steel sample 18HN3MA-SH. There is a clear change in the layer structure with distance from the sample surface.

Table 3. The amplitude of internal stresses in various morphological components of ferrite and perlite in steel 18HN3MA-SH in the initial condition

\begin{tabular}{|c|c|c|c|c|}
\hline \multirow{2}{*}{ Morphological components } & \multirow{2}{*}{$\begin{array}{c}\text { Shear stress } \\
\text { amplitude } \\
\sigma \mathrm{MPa}\end{array}$} & \multicolumn{3}{|c|}{ Amplitude of moment voltages, $\sigma_{\partial} \mathrm{MPa}$} \\
\hline & & $\sigma_{\partial}$ & $\sigma_{\text {пл. }}$ & $\sigma_{\text {упр. }}$ \\
\hline \multicolumn{5}{|c|}{ Perlite grains } \\
\hline Unfragmentedferrite & 370 & 260 & 260 & 0 \\
\hline Fragmentedferrite (largefragments) & 350 & 350 & 350 & 0 \\
\hline Fragmentedferrite (small fragments) & 220 & 770 & 220 & 550 \\
\hline In ferritegrains & 330 & 1530 & 140 & 1390 \\
\hline \multicolumn{5}{|c|}{ Perlite grains } \\
\hline Weaklydefectiveperlite & 300 & 260 & 260 & 0 \\
\hline Destroyedpearlite & 300 & 1520 & 300 & 1220 \\
\hline Fragmentedperlite & 240 & 2390 & 240 & 2150 \\
\hline Fragmented structure with parts of $\mathrm{M}_{23} \mathrm{C}_{6}$ & 460 & 3910 & 460 & 3450 \\
\hline In perlite grains & 290 & 2360 & 290 & 2070 \\
\hline Materialaverage & 300 & 1330 & 300 & 1030 \\
\hline
\end{tabular}

As research have shown, the phase composition and volume fraction of the phases of 18HN3MA-SH steel after carbonitriding changes as the sample goes deep into the sample. As a result of the research, it was found that the material 
of the surface layer is multiphase [17]. It must be emphasized that, firstly, the shape of the particles of the phases present, their size and mutual arrangement are different and, secondly, the particles of all phases are surrounded by the $\alpha$-matrix.

Internal stresses in steel after carbonitrizationare determined by several factors. The first factor is the number of carbon and nitrogen atoms or, in other words, the concentration $(\mathrm{C}+\mathrm{N})$ introduced into the steel. It is known [18] that in the $\alpha$-phase these elements are poorly soluble. In the $\gamma$-phase, their solubility is much greater. In the process of carbonitriding, as we expected, the lattice defects were first saturated, then the $\gamma$-phase and then $\alpha$-phase, and the formation of carbides, nitrides and carbonitrides began. A significant proportion of the implantation elements were localized on defects in the crystal structure, especially at the grain boundaries. Subsequently, carbides and carbonitrideswere formed there. We know [19] how the parameters of the crystal lattices of the solid solutions of the $\alpha$ - and $\gamma$-phases based on iron depend on the concentration of carbon and nitrogen (these formulas are given in Table 4).

Table 4: Type, space group and parameters of crystal lattices of $\alpha$ - and $\gamma$-phases, carbides and carbonitrides in steel

\begin{tabular}{|c|c|c|c|c|c|}
\hline \multirow[t]{2}{*}{ Phase } & \multirow[t]{2}{*}{ Type of crystal lattice } & \multirow[t]{2}{*}{ Space group } & \multicolumn{3}{|c|}{$\begin{array}{c}\text { The parameters of crystal } \\
\text { lattice, } \mathrm{nm}\end{array}$} \\
\hline & & & \begin{tabular}{l|l}
$a$ & \\
\end{tabular} & \begin{tabular}{l|l}
$b$ \\
\end{tabular} & $c$ \\
\hline$\alpha$-phase & $\mathrm{BCC}$ & $\operatorname{Im} 3 \mathrm{~m}$ & \multicolumn{3}{|c|}{0.2866} \\
\hline$\gamma$-phase & FCC & Fm3m & \multicolumn{3}{|c|}{0.3600} \\
\hline $\mathrm{Cr}_{12} \mathrm{Fe}_{32} \mathrm{Mo}_{7} \mathrm{Ni}_{7}$ & Cubic & $\mathrm{I} 43 \mathrm{~m}$ & \multicolumn{3}{|c|}{0.8900} \\
\hline $\mathrm{M}_{3} \mathrm{C}$ & Orthorhombic & Pnma & 0.5080 & 0.6774 & 0.4520 \\
\hline $\mathrm{M}_{23}(\mathrm{C}, \mathrm{N})_{6}$ & FCC & Fm3m & \multicolumn{3}{|c|}{1.0585} \\
\hline $\mathrm{M}_{2} \mathrm{C}_{0.61} \mathrm{~N}_{0.39}$ & Orthorhombic & Pbcn & 0.4878 & 0.5604 & 0.4440 \\
\hline $\mathrm{M}_{6.2} \mathrm{C}_{3.5} \mathrm{~N}_{0.3}$ & Orthorhombic & Ama2 & 0.6956 & 0.9260 & 0.2844 \\
\hline $\mathrm{M}(\mathrm{CN})_{2}$ & Tetragonal & - & \multicolumn{2}{|c|}{0.6832} & 0.3200 \\
\hline$\beta$-graphite & Hexagonal & $\mathrm{P}_{3} / \mathrm{mmc}$ & \multicolumn{2}{|c|}{0.2547} & 1.0044 \\
\hline
\end{tabular}

How the parameters of the crystal lattices increase with the introduction of carbon and nitrogen into them from these formulas we can see. In the formation of nitrides and carbides, similar changes occur in the bulk and linear dimensions of the samples. Since they do not proceed immediately in the whole volume, but, starting from the surface, the process of carbonitriding is accompanied by the appearance of significant internal tensile-compression stresses in steel.

The specific volume per atom in carbides and carbonitrides is greater than the specific volume of the solid solution. Therefore, if the introduction elements form carbides and carbonitrides, then the volume and linear dimensions of the material will increase. Then the degree of growth of internal stresses will be determined by the possibility of plastic relaxation around new carbides and carbonitrides. Being located at the boundaries and in the junctions of the grains, these particles less increase the level of internal stresses compared to their location away from lattice defects.

The next factor is the degree of coherence "carbide - metal". Incoherent allocations, as a rule, create a lower level of stresses than coherent ones; semi-coherent occupy an intermediate position. It should be noted that coherent, semicoherent, and incoherent precipitates are also present in the studied steel. In addition to the "matrix - selection" border type, the shape of the discharge plays an important role. It is connected by the ratio of the elastic modules of carbide and metal with the energy of the interface at its different orientations. Under various conditions, flat discharge, ellipsoidal or spherical, is less stressed. In the studied steel there are secretions of the most diverse forms.

Another factor determining the level of internal stress fields is the correlated arrangement of carbides in space. It leads to a decrease in the field of internal stresses. 
The second contribution to the stress field is created by dislocations organized into a substructure.

Carbonitrization leads to the accumulation of a high scalar dislocation density in the material in the research of steel. Its average value reaches $4 \cdot 4 \cdot 10^{10} \mathrm{~cm}^{-2}$ (Table 5).

Such a dislocation structure, naturally, will form large internal stresses. In addition, the dislocation structure formed in steel, along with the scalar density of dislocations, is characterized by a high value of excess dislocation density $\left(2.9 \cdot 10^{10} \mathrm{~cm}^{-2}\right)$. The latter will also cause high internal stress fields (momentary stresses), which are identified by the presence of extinction circuits in the material.

The third contribution to the internal fields is created by disclinations [20], which are located at the joints of the packages and the joints of the packages and plates. In these places, butt disclinations are sources of stress fields [21].

An important role in the formation of the stress spectrum is played by cracks formed in the material. The tip of the crack serves as a stress concentrator [22]. The contribution from cracks is the fourth contribution to the internal stress fields.All the listed sources of internal stresses are present in the studied steel.

As the conducted studies by electron microscopy have shown, firstly, the dislocation structure in the studied steel is represented mainly by dense dislocation networks. Secondly, the dislocation structure is strongly polarized. And, thirdly, the scalar dislocation density $\rho$ is close to the excess dislocation density $\rho_{ \pm}$, i.e. $\rho \approx \rho_{ \pm}$(table 5). All this means that the scalar dislocation ensemble is fundamental in the formation of the internal stress field. In addition, the sources that form internal stresses in the material under study are heterogeneity of the concentration of implantation elements (carbon and nitrogen), the presence of carbides and carbonitrides.

Table 5: Quantitative characteristics of the dislocation structure in different morphological components of $\alpha$ martensite and on average by material. The transition layer of nitrocemented steel 18HN3MA-SH

\begin{tabular}{|l|c|c|c|}
\hline \multirow{2}{*}{ Morphological component } & $\begin{array}{c}\text { Volume fraction of the } \\
\text { morphological component }\end{array}$ & $\rho\left(\times \mathbf{1 0}^{\mathbf{1 0}}\right)$ & $\boldsymbol{\rho}_{ \pm}\left(\times \mathbf{1 0}^{\mathbf{1 0}}\right)$ \\
\cline { 3 - 4 } $\mathbf{c m}^{-\mathbf{2}}$ & 5.3 & 2.5 \\
\hline Batch martensite & $40 \%$ & 4.1 & 3.5 \\
\hline Lamellarlow-temperaturemartensite & $25 \%$ & 3.5 & 2.9 \\
\hline Lamellarhigh-temperaturemartensite & $35 \%$ & 4.4 & 2.9 \\
\hline Materialaverage & $100 \%$ & 5 \\
\hline
\end{tabular}

So, using formulas (1) and (2), shear stresses $\sigma$ and moment stresses $\sigma_{\partial}$ were calculated in all morphological components of $\alpha$-martensite and, in general, for the material for nitro cemented steel 18HN3MA-SH in the transition layer (Table 6). Here we emphasize once again that in the surface layer in the $\alpha$-phase bending extinction contours were not found (or their width was large). Therefore, we believe that the moment stresses in the surface layer are absent. The amplitude of the shear stress calculated by the formula (1) made up the value $\sigma=460 \mathrm{MPa}$.

Table 6: Amplitude of internal stresses in different morphological components of $\alpha$-martensite and on average by material. The transition layer of nitrocemented steel 18HN3MA-SH

\begin{tabular}{|l|c|c|c|}
\hline \multicolumn{1}{|c|}{ Morphological component } & $\begin{array}{c}\text { Volume fraction of the } \\
\text { morphological component }\end{array}$ & $\begin{array}{c}\text { Shear stress } \\
\text { amplitude } \\
\boldsymbol{\sigma} \mathbf{~ M P a}\end{array}$ & $\begin{array}{c}\text { Amplitude of } \\
\text { momentary } \\
\text { stresses, } \boldsymbol{\sigma}_{\boldsymbol{\delta}} \mathbf{M P a}\end{array}$ \\
\hline Batchmartensite & $40 \%$ & 460 & 320 \\
\hline Lamellarlow-temperaturemartensite & $25 \%$ & 400 & 370 \\
\hline Lamellarhigh-temperaturemartensite & $35 \%$ & 370 & 340 \\
\hline
\end{tabular}




\begin{tabular}{|l|c|c|c|}
\hline Materialaverage & $100 \%$ & 420 & 340 \\
\hline
\end{tabular}

As see from Table 6, first, the amplitude of shear stresses is always greater than the amplitude of the moment stresses. Secondly, the moment stresses are purely plastic. Thirdly, compared with the initial state of steel, the torque stresses are significantly lower, i.e. carbonitrization has led to a decrease in internal stresses.

\section{CONCLUSIONS}

It was determined that 18HN3MA-SHsteel in the initial state belongs to the ferrite-pearlite class and consists of ferrite grains $(\sim 20 \%)$ and pearlite $(\sim 80 \%)$. Studies have shown that all components of ferrite and perlite have a different set of carbide phases and are characterized by different scalar and excessive density of dislocations.

It was found that the average scalar density of dislocations in ferritic grains is 2 times less than in pearlitic ones. It was also found that in fragmented ferrite with small fragments, the magnitude of the scalar density of dislocations was lower, which confirms the straight-line relationship $\rho$ with the size of grains containing a network dislocation structure.

It was revealed that in the destruction of the pearlite structure, carbon leaves the crystal lattice of the cementite, which leads to the destruction of the plate of cementite, the formation of carbides of a special type.

It has been established that the scalar dislocation ensemble is fundamental in the formation of the internal stress field, since the scalar dislocation density $\rho$ is almost equal to the excess dislocation density $\rho_{ \pm}$i.e. $\rho \approx \rho_{ \pm}$. Thus, it can be argued that the main sources of internal stress fields in the initial state of steel are: scalar dislocation density, polarization of the dislocation structure and excess dislocation density.

Research have shown that after nitrocementation in electrolytic plasma, the shape of the particles of the phases present in steel 18XH3MA-III, their size and mutual arrangement are different, and also the particles of all phases are surrounded by the $\alpha$-matrix.

The results of the study showed that the dislocation structure in the steel under study is represented by dense dislocation grids, which is strongly polarized. This means that the scalar dislocation ensemble is fundamental in the formation of the internal stress field. It was found that the sources that form the internal stresses in the material under study are heterogeneity of the concentration of implantation elements (carbon and nitrogen), the presence of carbides and carbonitrides.

It follows from the obtained calculations that the amplitude of shear stresses is greater than the amplitude of the moment stresses, which are purely plastic in nature. Also, in comparison with the initial state of steel, the torque stresses were significantly lower, i.e. electrolyte-plasma nitrocementation led to a decrease in internal stresses.

\section{REFERENCES}

1. Sosnin N.A., Ermakov S.A., Topolyansky P.A. (2008). Plasma technology. Welding, coating, hardening. M.: Mashinostroenie, 406.

2. LakhtinYu.M., KoganYa.D. (1976). Nitriding of steel. - M.: Mechanical engineering, 256.

3. Koneva N.A., Kozlov E.V., Trishkina L.I. (2001). The internal sources, their materials, and their flow stress / Materials Science and Engineering, V. 319-321, 156-159. 
4. Skakov M.K., Uazyrkhanova G.K., Popova N.A., Scheffler M. (2013). Influence of Deformation on the Phase-Structural State of 30CrMnSiA Steel / Materials Testing, №1 (55), 51-54.

5. MazhynSkakov, LyailaBayatanova, Michael Scheffler. (2014). Electrolytic Plasma Treatment Examination, No. 7-8 (56), 622628.

6. Kozlov E.V., Popova N.A., Koneva N.A. (2011). Scalar dislocation density in fragments with different types of substructures // Letters on materials, V. 1, 15-18.

7. Gromov V.E., Kozlov E.V., Bazaikin V.I. and others. (1997). Physics and mechanics of drawing and forging. - M.: Nedra, 293.

8. Koneva N.A., Trishkina L.I., Kozlov E.V. (1998). Spectrum and sources of internal stress fields in deformed metals and alloys // Izvestia AN. A series of physical, V. 62, №7, 1350-1356.

9. Mader S., Seeger A., Leitz K. (1967). Strain hardening and distribution of dislocations in fcc metals // Structure and mechanical properties of metals. - M.: Metallurgy, 9-41.

10. Hirt J., Lotte I. (1972). Theory of dislocations. - M.:Atomizdat, 599.

11. Levine, L., Geantil, P., Larson, B., Tischler, J., Kassner, M., Liu, W., Stoudt, M., Tavazza, F. (2011). Act. Materialia. № 59, 580-581.

12. Skakov M.K., Uazyrkhanova G.K., Popova N.A. (2013). Electron microscopic analysis of 30CrMnSiA steel surface layers after hot deformation // Applied Mechanics and Materials, V. 395-396, 336-34.

13. Rusakov A.A. (1977). Radiography of metals. - M.: Atomizdat, 479.

14. B. Strunin(1967). On the distribution of internal stresses with a random arrangement of dislocations / FTT, V.9, No. 3, 805812.

15. Panin V.E., Likhachev V.A., GrinyaevYu.V. (1985). Structural levels of deformation of solids. - Novosibirsk: Science, 229.

16. Popova N.A., IvanovYu.F., Koneva N.A. et al. (2007).Internal stress fields in austenitic and martensitic steels, their sources and nature / Ed. A.I. Potekaeva // Evolution of the structure and properties of metallic materials. Tomsk: Publishing house NTL,351-384.

17. Skakov M.K., Bayatanova L.B., Popova N.A. (2014). TEM - studies of the structure and phase composition of steel 18HN3MASh after exposure to electrolytic plasma // Bulletin of KazNTU named after K.I. Satpayev, № 3 (103), 487-493.

18. Bannykh O.A., Budberg P.B., Alisova S.P. (1986). State diagrams of binary and multicomponent iron-based systems (Reference). - M .: Metallurgy, 440. 
19. Kurdyumov G.V., Utevsky L.M., Entin R.I. (1997).Transformations in iron and steel. - M.: Science, 236.

20. Rybin V.V. (1986). Large plastic deformation and destruction of metals. - M.: Metallurgy, 224.

21. Kozlov E.V., Popova N.A., Koneva N.A. (2004). Fragmented substructure, which is formed in BCC steels during deformation, Izv. RAS. A series of physical, V. 68, №10, 1419-1428.

22. MeshkovYu.Y., Pakharenko G.A. (1985). Metal structure and brittleness of steel products. - Kiev: NaukovaDumka, 208. 